\title{
KETOSIS AND COMA IN DIABETES MELLITUS
}

\author{
By B. A. Young, M.D., M.R.C.P.
}

Physician, St. Alfege's Hospital; Physician-in-Charge, Diabetic Clinics, St. Alfege's and Miller Hospitals, Greenuich

During recent years new ideas on certain aspects of the mechanism and treatment of diabetic ketosis and coma have developed, supported by a considerable amount of clinical and experimental evidence. This paper attempts to bring together some of the newer views, and the opportunity is taken of reiterating some old ones.

\section{Mechanism of Ketosis}

Ketosis results from the accumulation in the blood of ketone bodies which are formed during the oxidation of fatty acids to produce energy. 'These substances, beta-hydroxybutyric acid, acetoacetic acid and, secondarily acetone, are produced during normal metabolism and are found in the blood of normal subjects (Barnes and Wick, 1939). It is only in fasting conditions in the normal and in cases of severe diabetes mellitus that ketone bodies accumulate in significant amounts. During fasting ketosis is due to insufficient ingestion of carbohydrates; in diabetes, to insufficient carbohydrate metabolism arising from lack of insulin. The diabetic ketosis, if uncontrolled, will proceed to a fatal coma, partly caused by ketotic intoxication and partly by the profound changes in electrolyte balance due to concomitant metabolic disturbances.

During the past decade theories of the mechanism whereby carbohydrate lack causes ketosis have changed considerably. The earlier conception of ketosis (Geelmuyden, 1904) was that a chemical union took place during the course of metabolism between carbohydrate and ketone bodies, resulting in a compound subsequently oxidized; a process harmless to the body. A ketogenic-antiketogenic ratio was postulated implying a quantitative relationship between the oxidation of ketones and glucose (Schaffer, 1923). If carbohydrate metabolism were deficient it was assumed that the chemical combination of glucose with fatty acid did not take place and that the ununited ketone bodies were liberated into the blood stream to produce ketosis.

Recent work has shown that the muscles of the body can absorb and oxidize large quantities of acetoacetic and beta-hydroxybutyric acid, the ketone bodies playing a part in metabolism in- dependent and not unlike that of glucose (Lawrence, 1942; MacKay, 1943; Young, 1944). These substances, formed by partial oxidation of fatty acids in the liver, are distributed to the tissues for complete combustion. MacKay (1943) suggested two forms in which fuel is supplied to the body, one in which fat is used directly by the tissues and the other whereby the glucose and ketone bodies secreted by the liver are oxidized to to produce energy. Glucose and ketones he describes as 'quick fuel.' Glucose is the only source of supply of 'quick fuel' to the brain and nervous system, whereas both glucose and ketones can be utilized by all other tissues. If available, glucose is the 'quick fuel' of choice; if unavailable the tissues, other than the brain, make up for the deficiency by oxidizing ketone bodies. In ketogenic states from 30 to 80 per cent. of the energy requirements of the body may be supplied by ketones (Barnes, et al., 1940), and during extended fasting it is possible that not more than ro per cent. of the total fuel requirements of the tissues are supplied by glucose (Drury, 1942). Ketone bodies are, therefore, no longer regarded as poisons necessarily harmful to the organism, being used equally efficiently as a source of energy in the ketosis of diabetes, of fasting conditions and in normal metabolism (MacKay, I943).

The danger of ketosis is one of degree and is dependent on the non-availability of carbohydrate as the ' quick fuel' of choice. In diabetes the intensity of the ketosis, particularly if it develops rapidly, contributes to the production of coma. Ketosis is not the only factor in the production of diabetic coma, which is the result of a generalized metabolic disturbance of which ketosis is a part. Evidence of ketosis and its degree is, however, a useful guide to the control of diabetes and the prevention and treatment of coma.

\section{The Mortality of Diabetic Coma}

In considering the mortality rates of diabetic coma reported by various writers comparison is difficult owing to the different clinical criteria, degrees of diabetic ketosis and to the many other variable factors involved. Rabinowitch (1939) and Collen (1942 a, b) analysed large series of patients 
suffering from diabetic coma in an effort to compile a formula for the calculation of a severity index on which to estimate the severity of ketosis and coma. Both conclude that the four most important factors affecting prognosis are, in order of significance, age, degree of unconsciousness, diastolic or systolic blood pressure and complicating diseases, particularly infection. Of less importance are duration of coma, blood nonprotein nitrogen and the blood sugar, the latter influencing the mortality to a slight degree and only in unconscious patients. Both writers state that the $\mathrm{CO}_{2}$ combining power of the plasma is of little or no importance in evaluating the severity of coma and bears no relation to mortality. This was confirmed by Nicholson (1947).

All writers find a negligible mortality in patients. with ketosis without disturbance of consciousness. Rabinowitch (1939) finds a 13.3 per cent. mortality with drowsiness, rising through $\mathrm{i} 6$ per cent. (semi-conscious) to 53 per cent. (unconscious but. responding to pain) and roo per cent. in completely comatose patients. Colleen (1942) reports a mortality rate of 83.8 per cent. in completely unconscious patients. Nicholson (1947) has a mortality of 48.8 per cent. in comatose patients irrespective of age, but with no complications. Franks (1947), using Collen's severity index (Collen, I942 a, b), finds a $3^{6}$ per cent. and $5^{2}$ per cent. mortality in severe cases of coma treated by two different methods. Joslin (1946) reports the lowest mortality of $\mathrm{ro}$ per cent. in unconscious patients of all ages, with a 33.5 per cent. fatality rate in 65 patients in the sixth decade, including conscious, drowsy and unconscious patients. These figures of patients treated by physicians of considerable experience, supported by teams of well-trained helpers, clearly demonstrate that diabetic coma is still responsible for a large number of fatalities, particularly in its later stages.

\section{Differential Diagnosis of Diabetic Coma}

The investigation of a suspected case of diabetic coma is not complete until a full and detailed physical examination of all systems has been undertaken. Two aspects only of the differential diagnosis will be considered.

Insulin reaction and diabetic coma. A differentiation between insulin and diabetic coma has to be made in diabetics. From the number of patients suffering from insulin reactions sent to hospital with a diagnosis of diabetic coma this would appear to be difficult. This is not so as there is little similarity, other than a state of unconsciousness, in the two conditions. The mode of onset of coma is important. The hypoglycaemic reaction is sudden, usually occurring in a healthy diabetic. Diabetic coma may advance rapidly but always supervenes on a previous state of ill health or acute illness. There is no dehydration in insulin coma, whereas in diabetic ketosis, which has progressed to coma, this should be an obvious feature. Air hunger is a most important sign of ketosis and is characteristic of this condition. An extensorplantar response is an almost constant accompaniment of insulin coma and is absent in ketosis unless co-existing cercbral disease is present. The smell of acetone in the breath and the large amount of ketoneuria in the comatose ketotic is never simulated by the hypoglycaemic patient. In rare cases of serious doubt a second specimen of urine taken a short time after the first, and still showing a heavy ketosis, will put the diagnosis of diabetic coma beyond doubt.

The diabetic acute abdomen. Abdicminal symptoms are commonly associated with diabetic ketosis. In the absence of any underlying inflammatory condition nausea, vomiting and intense pain occur, the latter often of a colicky nature and usually preceding the vomiting. There may be general or local abdominal tenderness and rigidity. The temperature is often raised and the pulse rapid. In ketosis a leucocytosis up to 50,000 W.B.C. is not uncommon (Lawrence, 1950). This condition, known as the diabetic acute abdomen, may therefore be very difficult to distinguish from diabetic ketosis associated with an acute surgical abdomen. The condition being more prone to develop in younger patients (Beardswood, I935), is frequently mistaken for acute appendicitis. Several theories of the cause of the condition have been put forward, none of which is convincing.

Active treatment of the dehydration and ketosis results in a rapid disappearance of abdominal symptoms as the ketosis improves. Failure of such a response makes laparotomy advisable. Serious though an unnecessary laparotomy during diabetic k.tosis may be, it is far less harmful than the results of an untreated peritonitis.

\section{Treatment of Diabetic Ketosis and Coma}

Diabetic coma is largely a preventable condition. Taken early the abolition of ketosis is relatively simple, once established, coma is commonly fatal. Prophylaxis consists of (a) the early diagnosis of the severe diabetic in whom symptoms and signs, including urinary findings, should make diagnos:s a simple matter, and (b) the education and regular supervision of established diabetics, preferably at a diabetic clinic with all the necessary facilities for the investigation and treatment of the disease and continuity of medical attention. The close co-operation between the clinic doctor, the diabetic and his general practitioner does much to abolish diabetic coma in a district served by an established diabetic clinic. 
The main principles in the treatment of diabetic ketosis and coma are: (I) to provide insulin in optimum dosage; (2) to replenish the dehydrated tissues with adequate amounts of fluid; and (3) to replace the electrolyte loss from the body, in particular those of chloride, potassium and phosphorus.

The treatment of diabetic ketosis (pre-coma) and of fully developed diabetic coma are two different problems and will be discussed separately.

I. Diabetic ketosis (pre-coma). Mild cases of ketosis without symptoms and signs, apart from a positive Rothera's test in the urine, may be treated as out patients by re-adjustment of the insulin dose. They should, however, be seen frequently and admitted to hospital should the condition not respond promptly.

More severe cases which have progressed to dehydration and drowsiness and show a heavy ketosis by the ferric chloride test require admission for intensive treatment. Such patients are conscious and can swallow, a fact which simplifies treatment considerably. If vomiting is severe intravenous fluids are necessary as for the treatment of coma ; if slight it will usually cease with treatment. Gastric lavage is very valuable in persistent cases. Most ketotic patients are constipated and require an enema.

It is my practice immediately to institute a four-hourly regime of insulin injection with glucose solution and fluids by mouth. In an adult an insulin dose of 24 to 40 units of soluble insulin is given followed by $50 \mathrm{~g}$. of glucose in $\frac{1}{2} \mathrm{pt}$. of water flavoured with 'diabetic' fruit juice. The insulin dose varies with the intensity of the ketosis and in very severe cases an initial dose of up to IOo units may be necessary. In the case of children half the adult dose is sufficient. Thereafter the bladder is emptied three hours following an insulin injection and again shortly before the next injection is due at the fourth hour. The second specimen is tested for sugar and ketones and the insulin dose adjusted accordingly. The following schedule is prescribed, according to the severity of the case, for the guidance of the nursing staff:

\begin{tabular}{c|c|c|c|c}
\hline $\begin{array}{c}\text { Urine } \\
\text { (Benedict's } \\
\text { Test) }\end{array}$ & Red & Yellow & Green & Blue \\
\hline Soluble insulin & $\begin{array}{c}\text { 40-24 } \\
\text { units }\end{array}$ & $\begin{array}{c}32-16 \\
\text { units }\end{array}$ & $\begin{array}{c}\text { I6-8 } \\
\text { units }\end{array}$ & Nil \\
\hline
\end{tabular}

The insulin injection is followed by $50 \mathrm{~g}$. glucose as before.

Between these feeds the patient is encouraged to take water flavoured with 'diabetic' fruit juice, tea with a little milk and Marmite made into soup or clear soup with the addition of salt. The progress of the patient is judged by the diminishing ketosis and no effort is made to render the urine sugar-free. Blood sugar control, although of interest, is not necessary.

In my experience the large majority of cases, even of severe ketosis, give no anxiety in this regime and lose all ketoneuria within 24 hours.

For the second 24 hours a high carbohydrate, low fat diet containing $200 \mathrm{~g}$. carbohydrate and not more than $15 \mathrm{~g}$. fat is prescribed, and soluble insulin given in three equally spaced injections during the day in a dose based on the patient's previous insulin requirements and needs during the period of ketosis. I do not use protamine zinc insulin in the treatment of severe ketosis, but during the third 24 hours a before-breakfast mixture of 2 to I soluble to protamine zinc insulin is given supplemented, if necessary, by soluble insulin before two other main meals.

This scheme of treatment is based on Himsworth's (1932) experience and has been used by me for the last 19 years. I have had no cause to amend it and have never failed to avoid the development of coma by its use in a ketotic, conscious diabetic patient.

2. Diabetic coma. The main general measures to be adopted in diabetic coma include the treato ment of shóck with warmth and stimulants. A enema should be given and a stomach wash-ou should not be omitted.

It is when insulin dosage, parenteral fluid administration and the replacement of depleted body electrolytes are considered that differences of opinion occur, and these aspects of treatment will be discussed separately.

(a) Insulin dosage. All are agreed that insulin should be given as early as possible in the treatment of diabetic coma. Root (1945) states that insulin given six hours after the onset of coma is worth, unit for unit, less than one-third of its value during the first hour. For this reason, provided the general practitioner is sure of the diagnosis, a great deal of good is done by the injection of 40 units of insulin while the patient is awaiting the arrival of an ambulance.

In considering the insulin dose to be given in the early hours of coma a balance must be struck be- . tween the optimum amount which can be utilized N by the patient and the dose which might precipitate hypoglycaemia. In the past it is probable that too low doses have been used initially. On the other hand recent papers have suggested high insulin doses which appear neither necessary nor $\stackrel{\mathbb{D}}{\rightarrow}$ safe for general use. Micks (1948) uses as much as 500 units of soluble insulin as the first dose, followed by roo units as frequently as every 1o minutes if improvement does not occur within an 
hour. Even pre-coma cases receive 100 units repeated half-hourly until improvement is obvious. Such doses have been criticized by Lawrence and Oakley (1948) and Dunlop and Donald (1948). Although the results of treatment have been good in the hands of this writer (Micks), the danger of severe hypoglycaemia would be very great if such dosage were adopted generally. Root (1945) and Joslin (1948) recommend a scale of dosage based on blood sugar levels giving 100 units of crystalline insulin subcutaneously if the blood sugar exceeds $300 \mathrm{mgm}$. per $100 \mathrm{cc}$., with an additional 200 units if it is between 600 and I,000 mgm. and a further 300 units if it is over $1,000 \mathrm{mgm}$. A proportion of the additional insulin is given intravenously in severe cases. At the third and sixth hours, with a rising blood sugar, 50 to 200 units are given by these authors according to the physician's judgment of progress. In stressing the need for high insulin dosage in the first three hours, Joslin et al. (I942) reports a mortality of I I per cent. in a series of 525 cases treated with an average of 83 units during the first three hours, and a subsequent series of 123 cases with a mortality of 1.6 per cent. treated with an average of 216 units in the first three hours. Not all these patients were in profound coma.

Lawrence's (1950) recommended dose is not so large, the initial injection in a very severe coma being 100 units repeated four hourly with a falling blood sugar, but increasing to 200 units with no blood sugar response. He states that he is not convinced that larger, or more frequently repeated doses, are more effective, and that the restoration of circulation by intravenous therapy, making the usual dose effective, is of more importance. Colwell (1950) stresses the need for higher initial insulin dosage, prescribing 80 to 200 units in the presence of severe dyspnoea and extreme lethargy and higher doses in cases with deep coma and failing circulation. He agrees with Lawrence in stating that if therapeutically effective doses are given initially it is unnecessary to repeat its administration until several hours have elapsed. Severe acidosis, he states, will not respond to insulin for three to five hours, even though it be given intravenously. He goes so far as to recommend a sixhourly administration schedule if response, as shown by physical signs, is favourable, and a four-hourly review and repeat of initial dose if symptoms fail to improve.

My own initial dose in coma cases with blood sugars of over $500 \mathrm{mgm}$. per $100 \mathrm{cc}$. is 100 to 150 units of soluble insulin subcutaneously and $5^{\circ}$ units intravenously. The patient is reviewed at the end of three hours in the light of improving circulation, diminishing ketosis, returning consciousness and, less important, falling blood sugar.
In the absence of response the insulin dose is repeated, and in severe cases may be doubled. Thereafter a three-hourly review is made and the original subcutaneous dose repeated or reduced according to the response to treatment. With the return of consciousness and the ability to retain fluids by mouth, the four-hourly regime outlined under pre-coma is commenced.

It is important to appreciate that a patient in diabetic coma has suffered from profound circulatory failure and that complete bed-rest is indicated for at least a week after recovery (Lawrence, 1950; Cooke, 1948).

(b) Correction of dehydration and chloride loss; saline and glucose administration. In recent years the question as to whether glucose or saline should be the initial parenteral fluid in coma cases has been the subject of much discussion. Himsworth (I93I, 1932) laid particular stress on the need for the early administration of glucose in the treatment of pre-coma with vomiting and coma, advocating the use of a ro per cent. solution. Experimental evidence in favour of early intravenous glucose has been advanced by Soskin et al. (1937), who showed that depancreatized, hepatectomized animals can metabolize large amounts of carbohydrate with glucose oxidation and abolition of ketosis provided blood sugars remain at high levels. It was shown (Mirsky et al., I94I) that ketosis was diminished or abolished in depancreatized animals, and in humans with diabetic acidosis, when sufficient carbohydrate was given. These observations suggested. that free carbohydrate administration was beneficial in diabetic coma.

Root (1945), the leading opponent of the early use of glucose, objects to its use on the grounds that (a) no more than 5 to $10 \mathrm{~g}$. of carbohydrate need be oxidized per hour in order to check ketone formation, (b) excessive hyperglycaemia is harmful to the pancreas, and (c) excessive glucose concentration damages the liver (Astwood et al., I942). Franks et al. (1947) in investigating two groups of ketotic patients treated with early intravenous glucose or saline, found that while they showed no difference in the rate of disappearance of ketoneuria, comparable doses of glucose were retained more efficiently, using a smaller insulin dose, with the lower blood sugar levels of the saline group. Further, they state, that owing to the hyperglycaemia, glycosuria and polyuria of the glucose series, the urinary output was nearly four times that of the saline group, resulting in a delayed restoration of the failing circulation and of cellular dehydration. A lower fatality rate in cases treated with saline only is reported in this paper, and it is suggested that glucose should be withheld 
for at least four hours from the beginning of treatment.

As will be discussed in the next section, potassium and phosphorus diuresis is known to occur during ketosis. It is possible that the continued diuresis produced by early glucose administration may increase this loss (Storey, I950; Butler et al., i 947).

That glucose should be administered after the initial period of treatment is not disputed even by those who strongly deprecate its use during the early hours. Joslin (I945) has stated that patients in diabetic coma should receive not less than Ioo g. of glucose during the first 24 hours. Root (I945) gives carbohydrate four to six hours after the beginning of treatment. Opinion, though remaining divided on the danger of the use of glucose in the early stage of diabetic coma, appears, in recent years, to have swung in favour of its avoidance during the first hours of coma both in America and in this country (Lawrence, quoted by Oakley, 1949; Dunlop and Donald, 1948; Dunlop et al., 1950; Brit. med. F., Editorial, 1948).

It is my practice to administer 2 to 31 . of normal saline during the first three hours, thereafter continuing with a 4.3 per cent. solution of glucose in normal saline or a 5 per cent. solution of glucose according to whether or not the chloride deficiency has been remedied, as shown by the appearance of chloride in the urine. Large quantities of intravenous fluid may be necessary during the first 24 hours of treatment to combat chloride and fluid loss in patients who may have a deficit of $26 \mathrm{~g}$. of sodium chloride and io per cent. of the body weight of water (Butler et al., 1947).

(c) Consideration of other electrolytes; potassium and phosphorus. During the development of diabetic ketosis, polyuria, often accompanied by vomiting, results in the well recognized diminution of extracellular fluid volume, with lowering of the serum sodium and chloride. Recently attention has been drawn to the large loss of potassium and phosphorus which also occurs. It has been estimated that in addition to $26 \mathrm{~g}$. of sodium chloride and ro per cent. of body weight of water, the average case of coma also loses $5 \mathrm{~g}$. of phosphorus (Butler et al., 1947) and 3 to $6 \mathrm{~g}$. of potassium (Danowski, I949). In the initial stages of diabetic coma, however, the cellular deficit of potassium is frequently marked by a rise in the serum potassium. This condition is brought about when the increased renal excretion of potassium fails to keep pace with the increased rate of release of the ion from the body cells and with contraction of extracellular volume. With the administration of insulin and parenteral fluid in the treatment of coma, entry of potassium into the cells occurs associated with improved glucose utilization. Potassium excretion decreases, extracellular volume expands and the rate of potassium liberation from the cells diminishes (Seldin et al., I949). The result is a considerable fall in serum potassium wi hin four to 24 hours of the beginning of treatment.

Aitken et al. (1937) demonstrated in a case of familial periodic paralysis, where the serum potassium level is low during paralytic attacks, that the serum potassium can be lowered to produce symptoms by the administration of large amounts of glucose by mouth, by the injection of insulin and especially by the combined injection of insulin and ingestion of glucose. Symptoms of potassium deficiency were produced when the serum potassium fell to below $12 \mathrm{mg}$. per $100 \mathrm{cc}$., the normal being 16 to $22 \mathrm{mg}$. Further studies of these cases (Allott and McArdle, 1938) showed that changes in phosphorus metabolism ran approximately parallel to those of potassium.

Holler (1946) was the first to describe a case of diabetic coma in which paralysis of the muscles of respiration ensued after treatment with large doses of insulin and parenteral 5 per cent. glucose in normal saline. In this case the serum potassium fell to $9.8 \mathrm{mg}$. per Ioo $\mathrm{cc}$. and recovery occurred, with a rising serum potassium, following parenteral and oral potassium administration. Frenkel et al. (1947) report a case similarly treated who developed circulatory collapse and respiratory failures with a serum potassium of $6.9 \mathrm{mg}$. per $\mathrm{I} 00 \mathrm{cc}$. Further cases have been described by Martin et al. (1947), Nicholson et al. (1947) and Tuynman and Wilhelm (1948).

Butler (1947) demonstrated a loss of serum phosphorus and potassium during investigations on a case of developing ketosis in a diabetic. $\mathrm{He}$ stressed the accentuation of this los; by increasing the metabolism of glucose and deposition of glycogen during treatment with insulin and glucose. Franks (1948) reports an initial rise in plasma inorganic phosphorus and in the excretion of phosphorus followed by a rapid fall with treatment in diabetic coma. The change in phosphorus serum levels ran parallel with those of potassium. He states that low phosphorus as well as low potassium serum levels may be responsible for circulatory collapse occurring after the abolition of ketosis, restoration of normal blood sugar, water and sodium chloride levels in diabetic coma.

The cycle of events taking place during the onset and treatment of diabetic ketosis may be summed up as follows:

(a) Loss of potassium by cells caused by vomiting, diuresis and dehydration. This may be accompanied by a high serum potassium.

(b) Insulin, glucose and saline therapy causing 
a shift of potassium from extracellular to intracellular spaces with a resulting low serum potassium level.

The movement of phosphorus in and out of the cells follows closely that of potassium.

Studies of electrocardiographic changes in relation to serum potassium levels have confirmed the occurrence of low values in diabetic acidosis. Falling potassium levels in man are associated with a progressive lowering and broadening of the $T$ wave and lengthening of the Q-T interval. This may proceed to a further lowering of the $T$ wave and depression of the $\mathrm{S}-\mathrm{T}$ segment leading to heart block and failure in systole (Stewart et al., I940; Stoll and Nisnewitz, I94I). Raised levels of serum potassium produce high, peaked $\mathrm{T}$ waves, increase in the duration of the Q.R.S. complex and heart failure in diastole (Winkler et al., I938). Serious disturbances may occur at concentrations above $7.0 \mathrm{~m}$. eq. per $1 .(28 \mathrm{mg}$. per $100 \mathrm{ml}$.) (Tarail, 1948). In a study of 44 patients with diabetic acidosis Nadler et al. (1948) correlated electrocardiographic changes with serum potassium levels. This paper describes the high or normal serum potassium E.C.G. curve before therapy with reversal to the low potassium type after treatment with insulin and glucose. It is suggested that electrocardiographic studies are useful in following serum-potassium levels during the treatment of acidosis.

The natural development of these biochemical and electrocardiographic findings has been the administration of potassium in cases of diabetic coma. Mention has been made above to cases successfully treated in this way. Emphasis should, however, be placed on the dangers of potassium intoxication which may follow its administration, especially by the parenteral route. The control of intravenous potassium therapy should be exercised by serial determinations of serum levels, and for quick results a flame photometer is necessary. Few hospitals in this country are so equipped, and electrocardiographic control may be a suitable alternative. Elkington and Tarail (1950), in an excellent survey of the present status of potassium therapy, give the following contraindications to potassium administration:

(a) Patients with renal insufficiency who may excrete potassium poorly.

(b) Patients with oliguria or anuria.

(c) Patients with raised serum potassium, as may occur in diabetic coma before treatment.

They stress that the danger of administering potassium to correct or prevent potassium loss is increased if the serum potassium level is not previously known. Joslin (1949) suggests that potassium administration should be limited to clinics where quick tests for potassium are avail- able. In my view this is wise in the case of parenteral administration.

Potassium salts may be administered orally, subcutaneously and intravenously. However dis- $c$. guised they are poorly tolerated when taken orally $\Rightarrow$ by patients with anorexia or vomiting. They have been given by stomach tube, to patients in diabetic coma, as potassium chloride in the following doses: 2 g. at short intervals (Frenkel, 1947); 0.6 g. doses to 3.6 g. total (Nicholson et al., I947); $5 \mathrm{~g}$. at half-hourly intervals for six doses (Tuynman et al., I948); $4 \mathrm{~g}$. left in the stomach after lavage (Lee et al., 1949). The phosphate salts are a more logical form of potassium administration since deficiency of extracellular phosphorus may co-exist with potassium in diabetic ketosis. Allott (personal communication) recommends a solution of potassium-dihydrogen phosphate $\left(\mathrm{KH}_{2} \mathrm{PO}_{4}\right)$, suitably flavoured, as being the most palatable in his experience in treating cases of familial periodic paralysis. $2 \mathrm{oz}$. of a solution containing $35 \mathrm{~g}$. $\mathrm{KH}_{2} \mathrm{PO}_{4}$ to $\mathrm{ro} \mathrm{oz}$. (with saccharin sol. gr. i, glycerin 3 iv, sol. essence of lemon 3 i added) will contain $2 \mathrm{~g}$. potassium. It is suggested that from the second or third hours of diabetic coma, provided a reasonable output of urine has been established, $2 \mathrm{oz}$. of this solution containing 2 gᄋ potassium can be administered by mouth two te three hourly with little risk of causing potassiura intoxication (see Lancet, Editorial, I95I). As the range of cellular potassium deficit in diabetic coma has been calculated to be, on an average, 228 to $936 \mathrm{~m}$.eq., or about 8 to $36 \mathrm{~g}$. of potassium in a $60 \mathrm{~kg}$. adult (Elkington and Tarail, 1950), smaller doses than the above, as have been suggested by other authors, would appear to be ineffective.

In the administration of parenteral potassium salts Elkington and Tarail (1950) recommend the avoidance of solutions with a concentration of potassium over 70 to 80 m.eq. (3 g.) per l., and a rate of infusion of above $20 \mathrm{~m}$.eq. (o.89 g.) potassium per hour. A solution containing $\mathrm{K}_{2} \mathrm{HPO}_{4} 4.5$ g., $\mathrm{KH}_{2} \mathrm{PO}_{4}$ r.o g. and $\mathrm{NaCl} 5.5$ g. to a litre, contains 60 m.eq. (2.4 g.) of potassium and should be given at a rate not exceeding $300 \mathrm{ml}$. per hour.

Hawkins et al. (195I) in treating a case of hypokalaemia associated with pyloric stenosis used an isotonic solution of potassium chloride, with hyaluronidase, subcutaneously to a total of $5.5 \mathrm{~g}$. of the chloride in four hours. When this dose was subsequently increased to $16.0 \mathrm{~g}$. given over eight hours signs of potassium intoxication developed, with a serum potassium level of $35 \mathrm{mgm}$. per 100 $\mathrm{ml}$.

Caution is therefore necessary in the use of potassium as a therapeutic agent. As it is probable that the fatalities which occur in diabetic coma, 
in spite of correction of ketosis, are due to serum and cellular potassium and phosphorus depletion, their use in the treatment of this condition is justified. If the precautions outlined above are observed it is probable that this addition to the therapy of diabetic coma may result in a reduction of the mortality of this still very fatal complication of diabetes mellitus.

\section{BIBLIOGRAPHY}

AITKEN, R. S., ALLOT, E. N., CASTLEDEAN, L. I. M., and WALKER, M. (1937), Clinical Science, 3, 47.

ALLOTT, E. N., and MCARDLE, B. (1938), Ibid., 3, 229.

ASTWOOD, E. B., FLYNN, J. M., and KREYER, O. (1942), f. Clin. Investigation, $2 \mathrm{I}, 62 \mathrm{I}$.

BARNES, R. H., and WICK, A. N. (1939), .7. Biol. Chem., 131, 413. BARNES, R. H., DRURY, D. R., GREELEY, P. O., and WICK A. N. (1940), Amer. F. Physiol., 130, 144.

BEARDSWOOD, T. J. (1935), F. Amer. med. Ass., 105, 1168.

Brit. med. F. (1948), Editorial, 2, 209.

BUTLER, A. M., TALBOT, N. B., BURNETT, C. H., STANBURY, J. B., and MACLACHLÄN, E. A. (1947), Tr. A. Amer. Physicians, 60, 102.

COLLEN, M. F. (1942a), Arch. intern. Med., 70, 347.

COLLEN, M. F. (1942b), Ibid., 70, 369 .

COLWELL, A. R. (1950), "Types of Diabetes and their Treatment,' Illinois, U.S.A.

COOKE, A. (1948), Brit. med. . ., ii, 799.

DANOWSKI, T. S., PETERS, J. H. RATHBUN, J. C., OUASH NOCK, J. M., and GREENMAN, L. (1949), $\mathscr{\exists}$. Clin. Investigation, 28, 1 .

DRURY, D. R. (1942), Ұ. Clin. Endocrinology, 2, 421.

DUNLOP, D. M., and DONALD, J. B. (1948), Brit. med. F., ii, 352.

DUNLOP, D. M., DAVIDSON, L. S. P., and MCNEE, J. W. (1950), 'Textbook of Medical Treatment,' Edinburgh.

ELKINGTON, J. R., and TARAIL, R. (1950), Amer. F. Med., 9, 200.

FRANKS, M., BERRIS, R. F., KAPLAN, N. O., and MYERS, G. B. (1947), Arch. intern. Med., 80, 739 .

FRANKS, M., BERRIS, R. F., KAPLAN, N. O., and MYERS, G. B. (1948), Ibid., 81, 42 .

FRENKEL, M., GROEN, J., and WILLEBRANDS, A. F. (1947), Ibid., 80, 728

GEELMUYDEN, H. D. (1904), Ztschr. f. physiol. Chem., 41, 128.

HAWKINS, T. F., HARDY, T. L., and SAMPSON, H. H. (1951), Lancet, $i, 318$.

HIMSWORTH, H. P. (1931), Ibid., ii, 978.

HIMSWORTH, H. P. (1932), Ibid., ii, 166.

HOLLER, J. W. (1946), F. Amer. med. Ass., 131, 1186.

JOSLIN, E. P., ROOT, H. F., WHITE, P., and MARBLE, A. (1942), F. Amer. med. Ass., 119, i 160.
JOSLIN, E. P. (1945), New. Engl. 7. Med., 232, 219.

JOSLIN, E. P. (1946), 'Treatment of Diabetes Mellitus,' 8th edition.

JOSLIN, E. P. (1948), Brit. med. F., ii, 651.

JOSLIN, E. P. (1949), F. Amer. med. Ass., 139, 1.

Lancet (195I), Editorial, i, 393.

LAWRENCE, R. D. (1942), Proc. R. Soc. Med., 31, I.

LAWRENCE, R. D. (1950), 'The Diabetic Life,' London.

LAWRENCE, R. D., and OAKLEY, W. (1948), Brit. med. F., ii, 3 I0.

LEE, J., NAIDOO, D., and TORRENS, J. A. (I949), Ibid., i, 565. MACKAY, E. M. (1943), F. Clin. Endocrinology, 3, ro1.

MARTIN, H. E., and WERTMAN, M. (1947), F. Clin. Investigation, 26, 217 .

MICKS, R. H. (1948), Brit. med. F., ii, 200.

MIRSKY, I. A. FRANZBLAU, A. N., NELSON, N., and NELSON, W. E. (194I), F. Clin. Endocrinology, I, 307.

NADLER, C. S., BELLET, M. D., and LANNING, M. (1948), Amer. F. Med., $5,838$.

Nicholson, W. M., and BRANNing, W. S. (1947), F. Amer. med. Ass., 134, 1272.

OAKLEY, W. (1949), Brit. med. F., i, 724.

RABINOWITCH, I. M., FOWLER, A. F., and BENSLEY, E. H. (1939), Ann. Int. Med., 12, 1403.

ROOT, H. F. (1945), F. Amer. med. Ass., 127, 557.

SCHAFFER, P. A. (1923), Medicine, 2, 375 .

SELDIN, D. W., and TARAIL, R. (1949), f. Clin. Investigation (Proc.), 28, 810.

SOSKIN, S., and LEVINE, R. (1937), Amer. F. Physiol., 120, 761. STEWART, H. J., SMITH, J. J., and MILHORAT, A. T. (1940), Amer. . Med. Sci., 199, 780 .

STOLL, B., and NISNEWITZ, S. (1941), Arch. intern. Med., 67, 755.

STORY, R. D., and ROOT, H. F: (1950), f. Amer. med. Ass., I44 86.

TARAIL, R. (1948), Amer. F. Med., 5, 828.

TUYNMAN, P. E., and WILHELM, S. E. (1948), Ann. Int. Med. 29, 356.

W INKLER, A. V., HOFF, H. E., ard SMITH, P. K. (1938 Amer. F. Physiol., 124, 478.

YOUNG, F. G. (1944), St. Thomas' Hospital Gaz., 42, 64.

\section{RUTHIN CASTLE, NORTH WALES}

A Clinic for the diagnosis and treatment of Internal Diseases (except Mental or Infectious Diseases). The Clinic is provided with a staff of doctors, technicians and nurses.

The surroundings are beautiful. The climate is mild. There is central heating throughout. The annual rainfall is $\mathbf{3 0 . 5}$ inches, that is, less than the average for England.

The Fees are inclusive and vary according to the room occupied.

For particulars apply to THE SECRETARY, Ruthin Castle, North Wales. 